\title{
Study of Anaemia in Children with Severe Acute Malnutrition
}

\author{
Dwivedi $D^{1}$, Singh $V^{2}$, Singh J3, Sharma $S^{4}$
}

\begin{abstract}
Introduction: Severe anaemia is a leading cause of paediatric morbidity, hospitalization, and mortality and it is very important co morbidity in children with severe acute malnutrition. Severe Acute Malnutrition (SAM) with anaemia has been shown to have 2.62 times higher mortality as compared to SAM with no anaemia. So this study was done to evaluate this co-morbidity further. The aim of present study was to determine the prevalence and type of anaemia and to evaluate the possible aetiologies of anaemia in severe acute malnourished (SAM) children. Material and Methods: In tertiary care hospital a cross sectional study was conducted over a period of 8 month with 100 cases of SAM children and 101 cases of normal children .In both cases disorders of primary haematological problem were excluded. Auto analysers were used to measure blood counts. Blood smear was analysed by pathology consultant of institute and recorded for all patients with anaemia. Grade of anaemia and morphologic type of anaemia was analysed. Data were entered in Excel spreadsheets and analysed using SPSS 20.0. Results: Patient with SAM $42 \%$ had moderate anaemia and $19 \%$ had severe anaemia in contrast $41.6 \%$ and $16.8 \%$ in NON SAM child respectively. Predominant morphologic type in SAM patient was macrocytic anaemia $(33 \%)$, while in controls microcytic anaemia (40.6\%) was more prevalent. Conclusion: There was a high prevalence of anaemia in SAM children. Major morphologic type in SAM children was macrocytic anaemia which may indirectly show vitamin B12 or folic acid deficiency in these children.
\end{abstract}

Key words: Anaemia, macrocytic, severe acute malnutrition.

\section{Introduction}

$\mathrm{M}$ alnutrition is India's silent crisis; some of the highest rates of child malnutrition and mortality in under-5 children in the world (twice that of sub-Saharan Africa) are seen here ${ }^{1}$. According to WHO estimates, India is one of the countries with the highest prevalence of anaemia. As per the National Family Health Survey (NFHS), there has been a decrease in prevalence of anaemia from $69.4 \%{ }^{1}$ to $58.4 \%$ (NFHS 4, 2015-2016) among children between 6-59 months but is still a major social and medical problem.
${ }^{1}$ Dr. Deepak Dwivedi, MD. PGDDN. Associate Professor, ${ }^{2} \mathrm{Dr}$. Veerendra Singh MBBS. DCH, Senior Resident, ${ }^{3}$ Dr. Jyoti Singh, MD. FIAP, Professor Paediatrics, ${ }^{4}$ Sangita Sharma, Clinical Nutritionist. All from the department of Paediatrics, Shyam Shah Medical College, Rewa, MP India.

\section{Address for correspondence \\ Dr. Deepak Dwivedi \\ Associate Professor Paediatrics \\ D-2/8, Doctors Colony, Rewa, \\ Madhya Pradesh 486001, India \\ Tel No; +918699189636 \\ E-mail: deepakdwi72@gmail.com}

\author{
Acknowledgements: None \\ Funding: Nil \\ Conflict of Interest: None \\ Permission from IRB: Yes
}

\section{How to cite}

Dwivedi D, Singh V, Singh J, Sharma S. Study of Anaemia in Children with Severe Acute Malnutrition. J Nepal Paediatr Soc 2017;37(3):250-253.

doi:http://dx.doi.org/10.3126/jnps.v37i3.18480

This work is licensed under a Creative Commons Attribution 3.0 License.

(c) (i) 
Severe anaemia is a leading cause of paediatric morbidity, hospitalization, and mortality and it is very important co morbidity in children with severe acute malnutrition $^{3,4,5,6,7}$. Severe Acute Malnutrition (SAM) with anaemia has been shown to have higher mortality as compared to SAM with no anaemia ${ }^{8,9}$. Not many studies have been conducted to evaluate this co morbidity of SAM and hence this study was done for analysis of incidence and types of anaemia prevalent in malnourished children.

\section{Material and Methods}

This observational cross sectional study was carried out in severe malnutrition therapeutic unit of a tertiary care hospital from central India from October 2015 to October 2016. An approval for the study was obtained from the Institutional Ethical Committee.

A total of 100 children aged 6 to 59 months with a diagnosis of SAM were included in the study as cases. Another 101 children were enrolled in the study as controls. In the present study consecutive sampling was done among the admitted patients from the hospital. Controls were taken from children who were of the similar age range and socioeconomic background, admitted in hospital due to causes other than SAM or its complications. Children with primary haematological disease were excluded from the study. Data regarding their age, sex, place of origin, and other presenting complaints were recorded in predesigned proforma.

Data collected from the mothers included age, sex, birth order, birth weight, education and occupation of father. Using standard methods, a single observer measured children's weight, height/length, head and mid-arm circumferences. Venous blood of child was drawn under aseptic precautions after due consent in first week of admission in SMTU. Auto analysers were used to measure blood counts. Blood smear was analysed by pathology consultant of institute and recorded for all patients with anaemia.

Definitions used for the study were:

1. Severe acute malnutrition (SAM): Defined by low weight-for-height/ length ( $Z$ score $<-3$ SD of median WHO child growth standards), a mid-upper arm circumference $<115 \mathrm{~mm}$, or presence of bilateral pitting edema ${ }^{4}$.

2. Anaemia: WHO's criterion for anaemia in children ages 6 month to 59 months with haemoglobin $(\mathrm{Hb})$ levels $<11 \mathrm{~g} / \mathrm{dL}$

3. Nutritional anaemia: A state wherein normal levels of $\mathrm{Hb}$ cannot be maintained by erythropoiesis due to deficiencies of one or more nutrients

\section{Morphologic classification of anaemia:}

Anaemia was defined and classified based on cell size: Mean corpuscular volume (MCV) and amount of $\mathrm{Hb}^{5}$.

1. MCV less than -2SD of normal for that age: microcytic anaemia.

2. MCV within normal range: Normocytic anaemia.

3. MCV greater than -2SD of normal for that age: macrocytic anaemia

4. Dimorphic anaemia: When two or more causes of anaemia (microcytic and macrocytic) act simultaneously

Classification of anaemia based on haemoglobin levels ${ }^{5}$

1. Mild anaemia: $10-10.9 \mathrm{~g} / \mathrm{dL}$

2. Moderate anaemia: $7-9.9 \mathrm{~g} / \mathrm{dL}$

3. Severe anaemia: $<7 \mathrm{~g} / \mathrm{dL}$

Leukopenia and thrombocytopenia was defined according to the normal values for the age of the child ${ }^{5}$. Based on above methodology and definitions both cases and controls were classified and mean values of various haematological indices were studied. Parents were explained about the purpose of the study and a written informed consent was obtained.

Statistical analysis: Data were entered in Excel spreadsheets and analysed using SPSS 20.0. Qualitative variables were compared using chi square test and quantitative variables were examined using student t-test. Mean values of quantitative variables were studied and standard error of mean was calculated. A $p$-value less than 0.05 was considered significant.

\section{Results}

A total of 100 children with severe acute malnutrition were enrolled in the study and 101 were taken as controls. Majority of children were male and maximum children were from middle and lower socioeconomic status. None of the controls had oedema (Table 1). Although mean age among controls was higher than cases children with same age range in both cases and controls were included in the study. Controls were mostly admitted with acute diagnosis like pneumonia (33.7\%), sepsis $(25.7 \%)$, bronchiolitis $(19.8 \%)$, seizures $(14.9 \%)$, dehydration $(7 \%)$, and meningitis $(5 \%)$, etc. (data not shown).

Mean haematological indices were studied and compared for both cases and controls. Mean Haemoglobin levels and Haematocrit levels were lower in SAM children as compared to controls but it was not 
Table 1: Baseline variables of the sample studied

\begin{tabular}{lcc}
\hline Variables & Cases & Controls \\
\hline Male & $62(62 \%)$ & $63(62.4 \%)$ \\
\hline Female & $38(38 \%)$ & $38(37.6 \%)$ \\
\hline Mean Age months (SEM 95\% Cl)* & $15.85(1.039)$ & $28.1(1.532)$ \\
\hline Mean Weight kg (SEM 95\% Cl) & $6.32(0.13)$ & $11.49(0.29)$ \\
\hline Length /height cm (SEM 95\% Cl)* & $71.16(0.82)$ & $85.37(1.16)$ \\
\hline Mid upper arm circumference cm (SEM 95\% Cl)* & $10.89(0.09)$ & $13.02(0.07)$ \\
\hline Oedema & $15(15 \%)$ & 0
\end{tabular}

*standard error of mean $95 \%$ confidence interval

Table 2: Mean haematological variables of the sample studied

\begin{tabular}{lccc}
\hline Variable & Cases & Controls & p-value \\
\hline Haemoglobin gm/dl (SEM 95\% Cl)* & $8.94(0.26)$ & $9.19(0.21)$ & 0.453 \\
\hline Hematocrit \% (SEM 95\% Cl)* & $26.74(0.79)$ & $27.97(0.57)$ & 0.207 \\
\hline Mean corpuscular volume fl (SEM 95\% Cl)* & $84.1(1.94)$ & $73.86(1.43)$ & $<0.001$ \\
\hline RBC count (SEM 95\% Cl)* & $3.45(0.12)$ & $3.76(0.08)$ & 0.03 \\
\hline Mean corpuscular haemoglobin pg/cell (SEM 95\% Cl)* & $28.86(0.82)$ & $25.12(0.48)$ & $<0.001$ \\
\hline Mean corpuscular haemoglobin concentration \% HB/cell (SEM 95\% Cl)* & $34.45(0.64)$ & $33.25(0.23)$ & 0.08 \\
\hline Red cell distribution width \% (SEM 95\% Cl)* & $22.89(0.75)$ & $19.62(0.50)$ & $<0.001$ \\
\hline Total leukocyte count cells per mm3 (SEM 95\% Cl)* & $10744(713.5)$ & $11963(592)$ & 0.189 \\
Neutrophil count \% & $45.16(1.48)$ & $50.32(1.55)$ & 0.017 \\
Lymphocyte count \% & $46.36(1.55)$ & $43.62(1.58)$ & 0.217 \\
\hline Platelet count x 106/mm3(SEM 95\% Cl)* & $2.74(0.02)$ & $2.89(0.15)$ & 0.553 \\
\hline
\end{tabular}

*standard error of mean $95 \%$ confidence interval

Table 3: Classification of various haematological indices and morphology

\begin{tabular}{lccc}
\hline Variable & Cases & Controls & p-value \\
\hline No anaemia & $15 \%$ & $18.8 \%$ & 0.897 \\
\hline Mild anaemia & $24 \%$ & $22.8 \%$ & $41.6 \%$ \\
\hline Moderate anaemia & $42 \%$ & $16.8 \%$ & 0.004 \\
\hline Severe anaemia & $19 \%$ & $40.6 \%$ & \\
\hline Microcytic anaemia & $23 \%$ & $26.7 \%$ & $13.9 \%$ \\
\hline Macrocytic anaemia & $29 \%$ & & \\
\hline
\end{tabular}

statistically significant. Total RBC count was less in SAM children. Mean MCV was significantly higher in SAM children as compared to controls. $\mathrm{MCH}$ was also higher in SAM children as compared to controls which were statistically significant but there was no significant difference between two groups in $\mathrm{MCHC}$. RDW was significantly higher in cases than controls (Table 2).

Prevalence of anaemia was $85 \%$ in SAM group which was $81.2 \%$ in controls although this finding was not statistically significant; most of the children had moderate anaemia in both groups. Prevalence of leukopenia was higher in SAM children (9\%) as compared to controls (2\%) which was statistically significant. Thrombocytopenia was more prevalent among cases but this finding was not statistically significant.

Morphology of the cells in various forms of anaemia was studied and it was found that major form of anaemia was macrocytic (33\%) in SAM children while microcytic $(40.6 \%)$ was more common in controls. This finding was statistically significant with $p$-value 0.004 (Table 3).

\section{Discussion}

Anaemia is a major morbidity associated with severe acute malnutrition. As per the operational guidelines on SAM, nearly $70 \%$ of children (6-59 months) with SAM have anaemia. Out of which, $26 \%$ mild anaemia, $40 \%$ moderate anaemia, and $3 \%$ severe 
anaemia $^{6}$. In our study, very high percentages (85\%) of malnourished children were found to be anaemic. Majority of SAM children had moderate anaemia (42\%). Most common type of anaemia in cases was macrocytic followed by microcytic and microcytosis was more common in controls. This finding was not in accordance of previous studies where studies have shown microcytosis ${ }^{7,8}$ as main type of anaemia also operational guidelines for SAM management put more stress on treating microcytic anaemia while macrocytic anaemia is ignored ${ }^{6}$. This high MCV may indicate deficiency of vitamin B12 and folic acid in these children which can be stressed when treating these children although vitamin B12 level and folic acid levels were not done in present study. RDW was significantly higher in SAM children as compared to controls which may show that anisocytosis is more prevalent in SAM children and that most of the children may have deficiency of both the nutrients.
On studying other parameter we found that prevalence of leukopenia was more in SAM children than controls. We could not find any study mentioning the status of leukocytes in SAM children although this finding was statistically significant in this study. Leukopenia may also be attributed to vitamin B12 deficiency in these children. Major limitation of present study is that serum levels of vitamin B12 and folic acid were not done as they are not part of standard management protocol of SAM children and resource limitation. Further studies with levels of vitamin B12 and Folic acid are recommended.

\section{Conclusion}

This study emphasises the fact that anaemia is prevalent in malnourished children and macrocytic anaemia is most common variant in this population.

\section{References}

1. International Institute for Population Sciences (IIPS) and Macro International. National Family Health Survey-3 (NFHS-3), 2005-2006, India: key findings. Mumbai: IIPS; 2007 267-268.

2. International Institute for Population Sciences (IIPS) and Macro International. National Family Health Survey-4 (NFHS-4), 2005-2006, India: key findings. Mumbai: IIPS; 2017.

3. Keerthiwansa J, Gajealan S, Sivaraja S, Subashini KY. Malnutrition and anaemia among hospitalised children in Vavuniya. Ceylon Med J [Internet]. 2014 [cited 2018 Apr 19];59(4). Available from: http://cmj. sljol.info/articles/abstract/10.4038/cmj.v59i4.7869. DOI:10.4038/cmj.v59i4.7869

4. Debnath DJ, Parulekar CV. Profile of under-five malnourished children admitted in a tertiary care teaching hospital in pune, India. Int J Prev Med 2014;5(7):882-6.

5. Devi RU, Krishnamurthy S, Bhat BV, Sahai A. Epidemiological and clinical profile of hospitalized children with moderate and severe acute malnutrition in South India. Indian J Pediatr 2015;82(6):504-10. DOI:10.1007/s12098-014-1671-5

6. Kumar R, Singh J, Joshi K, Singh HP, Bijesh S. Comorbidities in hospitalized children with severe acute malnutrition. Indian Pediatr 2014;51(2):125-27.

7. Yaikhomba T, Poswal L, Goyal S. Assessment of iron, folate and vitamin B12 status in severe acute malnutrition. Indian J Pediatr 2015;82(6):511-14. DOI:10.1007/s12098-014-1600-7
8. Girum T, Kote M, Tariku B, Bekele H. Survival status and predictors of mortality among severely acute malnourished children $<5$ years of age admitted to stabilization centers in Gedeo Zone: a retrospective cohort study. Ther Clin Risk Manag 2017;13:101-10. DOI: $10.2147 / T C R M . S 119826$

9. Jarso $H$, Workicho A, Alemseged F. Survival status and predictors of mortality in severely malnourished children admitted to Jimma University Specialized Hospital from 2010 to 2012, Jimma, Ethiopia: a retrospective longitudinal study. BMC Pediatr 2015 Available from: https://www.ncbi.nlm.nih.gov/pmc/ articles/PMC4502938. DOI: 10.1186/s12887-0150398-4

10. Kleigman RM, Stanton BF, Schor NF, Geme JWS. Nelson textbook of Pediatrics. In: Stanley F Lo ed. Reference Intervals for Laboratory Tests and Procedures. $20^{\text {th }}$ ed. Elsevier: 2016. p. 3465-3466.

11. Ministry of Health and Family Welfare. Operational guidelines on facility based management of children with severe acute malnutrition. New Delhi: Ministry of Health and Family Welfare, Government of India; 2012.

12. Thakur N, Chandra J, Pemde H, Singh V. Anemia in severe acute malnutrition. Nutr Burbank Los Angel Cty Calif 2014;30(4):440-42. DOI:10.1016/j. nut.2013.09.011

13. Desai N, Choudhry VP. Nutritional anemia in protein energy malnutrition. Indian Pediatr 1993;30(12):147183. 